\title{
AUTOMATIC SANITARY NAPKIN VENDING AND DISPOSAL MACHINE
}

\author{
V. M. Pimpalkar \\ Asst. professor, Department of Electrical Engg. \\ Ballarpur Institute of Technology, Ballarpur, India \\ Suraj G. Satpute \\ Student, Department of Electrical Engg. \\ Ballarpur Institute of Technology, Ballarpur, India
}

\author{
Dhanshri B. Marbonwar \\ Student, Department of Electrical Engg \\ Ballarpur Institute of Technology, Ballarpur, India \\ Akash S. Lohkare \\ Student, Department of Electrical Engg \\ Ballarpur Institute of Technology, Ballarpur, India
}

\begin{abstract}
Nowadays women are leading their countries. They are working all over and playing important role in development. During the time of work their health, hygiene should be taken care especially at the time of menstruation. During menstruation women has to regularly change sanitary napkin in every 5-6 hours. Thus, easy availability of napkin is necessary. Use of napkins not only contribute towards women hygiene but also creates lots of plastic hazard results in environmental pollution. Uses of napkins are necessity but disposal of it is mandatory. The solution of both of this problem is installing automatic sanitary napkin vending and disposal machine. Fabrication of both vending and disposal machine will provide an easy availability of napkin and disposal of napkin at the same time in hygiene manner. This system aims to work on solar powered intelligent sanitary napkin vending and disposal machine. Both machines are operated in fully automatic manner. The machines can be transportable. In vending machine, the person can refill napkins when stoke is out. It can be possible by easy way to him due to automatic message send on his mobile. This machine can be used in industries due to use of RFID card. Disposal machine is eco-friendly. Use of double chamber in machine makes it more hygienic. Ash generated after disposal can be flash out easily or can be used as manure for plants by installing vending and disposal machine in school, collages, industry and in rural areas contribute towards eco-friendly environment.
\end{abstract}

Keywords: RFID (Radio Frequency Identification), UID (Unique Identification), IR proximity sensor (Infrared Proximity sensor), PIC (peripheral Interfacing controller)

\section{INTRODUCTION}

We are living in a 21 st century and human is making development to next level but one main problem arising with this development is health. Social status with health in equalities plays important role to serve the country. According to world health organization, worst health of people is due to lower social economics. Therefore, the solution on this problem is necessary. In all over the world out of total health issue women contribute most of the percent. Thus, women hygiene is most important and is needed to be take care. Most of the health problems of women are cause due to menstrual cycle. Due to unavailability of facilities, almost $23 \%$ of girls drop out the school during the time of menstruation. Women in India are still shy of buying napkin from medical shops and other stores. Thus, proper awareness and availability of napkin is very much important. A solution to this problem is installing automatic sanitary napkin vending machine in school, college and public places, working and educational institutions, it would help them to get the napkins as and when they needed.

On an average, each woman uses more than 10,000 sanitary napkins during menstrual cycle. Blood soiled sanitary napkins are favorable medium for disease causing bacteria such as Escherichia coli and viruses to grow rapidly. According to research, when blood on used sanitary pads is exposed to the air, approximately 100,000 bacteria will grow on it in a four minute. The red blood cells in the menstrual blood nourish the bacteria and emit a foul odour when they die. This cause a major pollution issue including lots of plastic waste. Thus, after use of sanitary napkin disposal is mandatory. So, we are proposing an eco-friendly sanitary napkin disposal machine. Vending machine to be fabricated and integrated with disposal machine, so that dispensing and disposing of napkin can be achieved in a single unit. 


\section{PURPOSE WORK}

Our first aim is to provide an easy way of availability of sanitary napkin to women's during the time of menstruation in normal and emergency condition. What make our machine different from others is that it can be transportable when needed. Also, when napkin in machine over it will automatically send message on mobile that stoke is out; thus, by an easy way we can control refill and removal of napkin. This work aims to develop an automatic sanitary napkin vending machine. It is control by Raspberry pi3Microprocessor. The vending machine is operated by automatic coin and RFID card mechanism. When the user inserts the coin or swipes the RFID card, the coin accepter or the RFID reader detects the coin or card and the relay is turn $\mathrm{ON}$ when a Raspberry pi 3 sends a signal to it results in to turn $\mathrm{ON}$ the Motor, which rotates the spring coil to vend a fresh napkin. After use of napkin, we are purposing an easy way of disposing napkin by fabricating vending machine with disposal machine.

Our second aim to make incinerator. Previously used machines have single chamber but our machine have two chambers which avoid smoke and dust problem. We also have a programable timer, which allows the machine automatically to switch $\mathrm{ON}$ and $\mathrm{OFF}$ after the set duration. The ash generated after disposal could either be used as manure for plants or can be flushed out. It is compact and has a packs number of features to save power. The entire system is packed completely in sheet metal box coated with anti-rust proof painting. This work aims to develop an automatic sanitary napkin disposal machine. Microcontroller used in project will turn on when a $5 \mathrm{~V}$ DC voltage is applied. When microcontroller turns $\mathrm{ON}$, automatically timer start at its initial state and temperature reading is display on LCD.12V DC supply turn ON relay which result in heating the coil of burner. The timer is being ready for 5 min to dispose of one napkin. When the burning is completed LED glows indicating that the process is completed after which the heater and really will turn off automatically. Also, there is another condition such a that if we put another napkin under process, the sensor present there sense another napkin and automatically increments the time of the timer by $5 \mathrm{~min}$ for which the timer is being programmed. Time is going increasing with quantity of napkin with $5 \mathrm{~min}$. Our system can burn 5 napkins at a time.

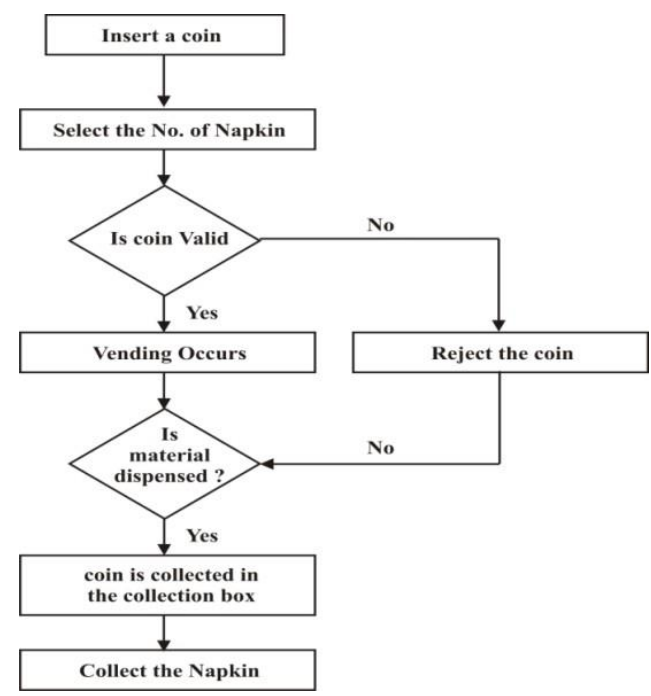

Fig a: Flow chart of Vending Machine

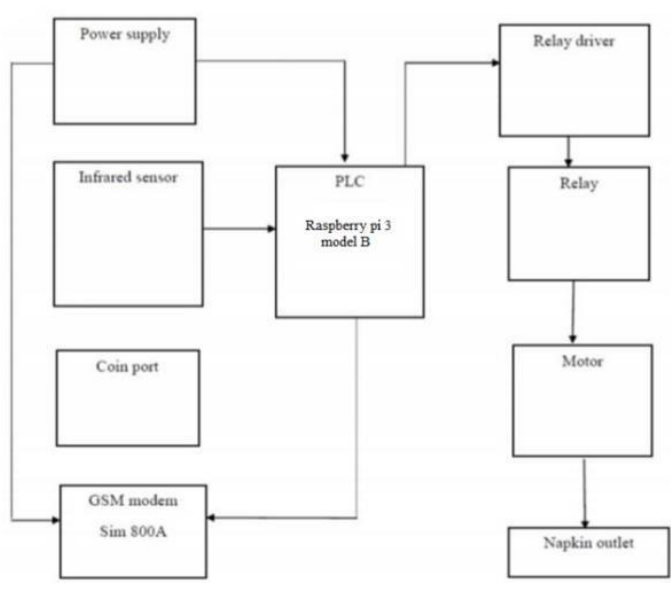

Fig b: block diagram of vending machine

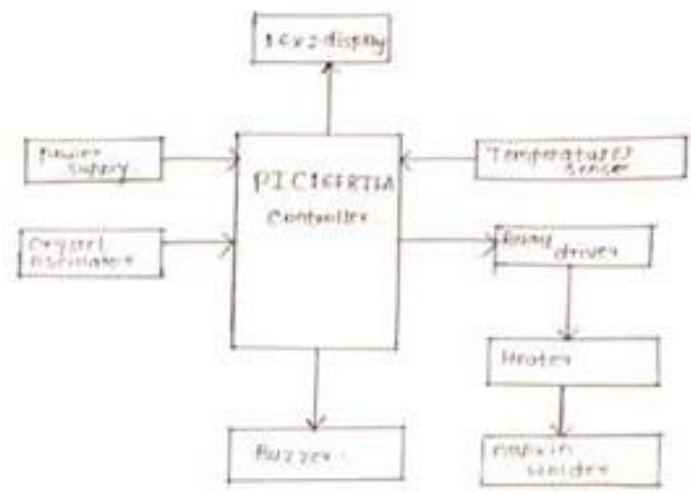

Fig c: block diagram of Disposal Machine

IV. COMPONENT USED

\subsection{For Vending Machine:}

A. Acrylic Material:

Acrylic material can use for casing of machine for following advantage - 


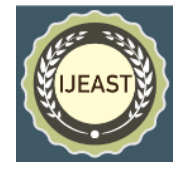

- This material has lightweight, thermoplastic and thermal insulation properties.

- It has attractive glossy surface that is available in clear or nearly any color.

- Acrylic withstands years of exposure to the elements and even corrosive atmospheres without losing its transparency, gloss or dimensional shape.

- It also will not darken or deteriorate from exposure to fluorescent light.

- Acrylic has good impact and chemical resistance. It can withstand high stresses for short periods

- IT is one of the most scratch-resistant thermoplastics.

- It can be stick on wall using silica jell without using screw and bolt.

B. Power supply:

We need a power supply of DC voltage $(5 \mathrm{~V})$ to run the servo motor, proximity sensor $(5 \mathrm{~V})$, relay $(5 \mathrm{~V})$, Coin acceptor unit, raspberry pi $3(5 \mathrm{~V})$. Due to some interruption of power supply, it has a provision i.e. battery. Battery can feed the power to the device and battery can be charged via the solar panel. This work uses a $12 \mathrm{~V}$ rechargeable battery.

\section{Raspberry pi 3:}

This work uses Raspberry Pi 3 Model B. It has used due to its features and performance. It introduces Raspberry Pi as a world's most inexpensive and powerful Single Board Computer. Ever since the launch of Raspberry Pi from 2012, this is worlds cheapest microprocessor unit specially built for learner and makers

The Raspberry pi 3 running raspberries serves as a master control over the other subsystem. It is a single board computer with microprocessor whereas Arduino is considered as microcontroller unit. The Raspberry pi is programmed in Python language. The first main task for the Raspberry pi is receiving and processing the UID from the scan RFID card. As the user drops the coin or swipes the RFID card, the coin acceptor or the RFID reader detect the coin or card and raspberry pi 3 send signal to turn on the relay.

D. Coin Acceptor unit:

Coin acceptor is a self- checkout application in vending of sanitary napkin. A coin acceptor is a device that is used in automated machines for accepting coins in exchange for goods or services. In this machine 5Rs. coin and 10Rs. coin is acceptable. If a consumer does not have 5Rs. change then they can insert $1 \mathrm{Rs}$ coin at 5 times. This coin acceptor is fully automatic that it will accept only 5,10 and multiple of $1 \mathrm{Rs}$. coin unless it will reject a dispenser.
E. 360 continuous rotation servo motor:

A continuous DC servo motor is used for rotation of spring. A servo motor plays an important role for vending a sanitary napkin. When users insert the coin or scratch RFID card, the coin acceptor detects the coin which give servo motor to turn ON. Motor ON automatically due to which napkin is vended. This work uses $12 \mathrm{~V}$ DC motor which is run by solar system.

\section{F. IR proximity Sensor:}

IR proximity sensor is a sensor able to detect the presence of nearby object without any physical contact. It can have a high reliability and long functional life because of absence of mechanical part and lack of physical contact between the sensed object. In this work, IR sensor has been used to detect the dropping of coin by the user. When no coin is put at the entrance of the coin port, the IR rays from the emitter reach the IR receiver and no action is taken by the system. But once the coin is put at the entrance of coin acceptor, it blocks the IR rays from reaching the receiver and this sends a signal to the microcontroller, which in turn switches $\mathrm{ON}$ a relay.

\section{G. RFID Reader:}

Radio Frequency Identification reader (RFID Reader) is a device used to gather information from an RFID tag which is used to track individual object. This is used to detect the RFID card. When the user requires sanitary napkin, user will scratch the RFID card, the reader detects the card to vend napkin.

\section{H. Automated Drawer:}

The drawer is used to allow dispensed product to be reach by the user. After the product drops down the drawer will open automatically allowing the user to get the product.

I. Relay:

Our system used two relays. One relay is used to switch ON the raspberry pi 3 and another is used to switch on the motor results in rotate the spring mechanism.

\subsection{For Disposal Machine:}

A. Power supply:

The system is connected to the AC mains i.e. $230 \mathrm{~V}$ AC. the power supply present in this system converts that $230 \mathrm{~V}$ AC into $5 \mathrm{~V}$ DC voltage required for it to turn $\mathrm{ON}$ microcontroller. When the system is turn $\mathrm{ON}$ another power supply converts $230 \mathrm{v}$ ac into $12 \mathrm{v}$ $\mathrm{dc}$ which is required for the relay to turn $\mathrm{ON}$. 


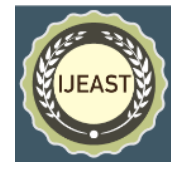

\section{B. Temperature Sensor (LM35)}

The LM35 temperature sensor is precision integrated circuit temperature device with an output voltage linearly proportional to centigrade temperature. The purpose for used of this sensor is small amount of constant voltage is subtracted from output to obtain convenient centigrade scaling. The device is used with single power supply. Sensor used in machine senses the set temperature and start burning of napkin when a napkin introduces in machine.

\section{Microcontroller (PIC16F877A):}

In this project when a $5 \mathrm{~V}$ dc voltage supply to the microcontroller it will turn $\mathrm{ON}$ once the micro controller turns ON. Initial state of timer i.e. ON/OFF a Temperature reading display on LCD. As system turn ON anther power supply convert $230 \mathrm{~V} \mathrm{AC}$ into $12 \mathrm{~V} \mathrm{DC}$ which is required for the relay to turn $\mathrm{ON}$, its start heating the coil of burner. Once the required heat to burn the Napkin is attend, the micro controller displays the Massage regarding the system being ready for the process.

\section{Heater:}

In this project, we are dealing with an effective solution to disposed menstrual waste with the help of disposal machine. For this purpose, the most commonly used heating coil made up of nichrome alloy is used. The sanitary napkins primarily surrounded by papers will have an ignition temperature of around 250 to $300 \mathrm{C}$. When the Sanitary napkin burns, it is reduced to ashes.

\section{E. Relay Driver (ULN2803):}

It is a high voltage, high current transistor array. When a 12 V DC supply given to it, is turn on it start heating the coil of burner.

\section{CONCLUSION}

As per study in India only $12 \%$ of women use sanitary napkins and percentage is much lower in rural areas. This is cause of lack of awareness among them. Women health is very sensitive and is needed to take care immediately and during the period of menstruation proper facilities are must provide. Most of the women in India are still shy of buying the napkins from shop or medical store. The solution on this problem is by installing automatic sanitary napkin vending machine in rural areas, school, collages, industries etc. Our aim is to provide an easy way of availability of napkin so that during emergency condition no problem should face by women. Use of sanitary napkin creates lots of Plastic waste as sanitary napkins are not bio-degradable which can cause major health issue and hazard to the environment. Most of the women throw used napkin in the garbage bin which gets mixed with dry, wet and cause a lot of plastic pollution as many of them don't know how to disposed them. So our work can give a solution on this problem by installing automatic sanitary napkin disposal machine. This machine operated in fully eco-friendly and hygienic manner. Thus, by installing it in areas can give a best message towards "SWACCHA BHARAT mission".

\section{RESULT}

The purpose of this work is to give an easy way of availability of napkin and dispose of it after use. Vending of napkin will done when user drops the coin or swipe the RFID card. The system works successfully when sensing of coin or RFID card is done. When stock of napkin in machine reach to minimum value, a SMS was sent and received by pre-set mobile number. It was observed that Disposal machine also work at its best when napkin introduce in it. Once machine reach to set temperature burning of napkin completed within set time. Thus, both of this system works properly for vending and disposal of sanitary napkin.

\section{ACKNOWLEDGEMENT}

We would like to show our deepest gratitude to prof. V. M. pimpalkar sir, Head of electrical Department. He is very supportive to us. He provided us a proper guideline to make our project success.

Mr. G.S. karlekar sir, professor at electrical Department, has also very helpful in motivation and support And there support make us to make something new and try latest technology.

\section{REFERANCE}

1] Fan Bai, Xiaochang Wang, (2011) Nitrogen Holding Property of the Composts in an Aerobic Mesophilic Composting Reactor for Sanitary Disposal of Human Feces, IEEE, vol.7, issue 11,

2] Jogdand K, Yerpude PA, (2011). Community based study on menstrual hygiene among adolescent girls. Indian Journal of Matern Child Health, Vol. 13, 1-6.

3] Suhail, Beg, (2014) "Implementation of FSM Based Automatic Dispense Machine with Expiry Date Feature Using VHDL," International Journal of Modern Engineering Research (IJMER), vol. 4, p.p. 15.

4] Singh, (2015) "Touch Screen Based Automated Medical Vending Machine," International Journal for Innovative Research in Science \& Technology (IJIRST), vol. 1, p.p. 1-4.

5] Linda scott, paul Montgomery, laurel stinfielt, Catherine dolan, (2013) Sanitary Pad Acceptabilityand Sustainability Study, University of Oxford.

6] Das, N., Mandal, R., Mitra, A., Maiti, B., Nandy, S., and Datta, D. (2018). FPGA Based Vending Machine.

7] Hossain, S., and Sen, V. (2018). Factors Influencing Hygienic Practices During Menses Among Girls From Jaipur, Rajasthan. International Journal Of Scientific Research, 6(11).

8] Rotary Club of kalyan, Sanitary Napkin Vending Machines and Disposal Machines for Girls in Rural Area School and College.

9] Knewron, (2013) "Any Time Medicine Vending 
Machine-Project Concept".

10] Check J., Schutt R. K. Survey research. In: J. Check, R. K. Schutt. (2012) editors. Research methods in education. Thousand Oaks, CA:: Sage Publications; pp. $159-185$

11] Jogdand K \& Yerpude PA, (2011) "Community based study on menstrual hygiene among adolescent girls", Indian Journal of Maternal and Child Health, Volume 13, Issue 3, pp. 1-6.

12] Sapkota D, Sharma D, Pokharel H. P, Budhathoki S. S \& Khanal V. K, (2014) "Knowledge and Practices regarding Menstruation among School going Adolescents of Rural Nepal", Journal of Kathmandu Medical College, Volume. 2, Issue 3, pp. 117-121.

13] Nagar S \& Aimol K. R, (2017) "Knowledge of Adolescent girls regarding Menstruation in Tribal areas of Meghalaya", Studies of Tribes and Tribals, Volume 8, Issue 1, pp. 27-30.

14] Thakre SB, Thakre SS, Reddy M, Rathi N, Pathak K \& Ughade S, (2011) "Menstrual hygiene: Knowledge and Practice among Adolescent school girls of Saoner, Nagpur District", Journal of Clinical and Diagnostic Research, Volume. 5, Issue 5, pp. 10271033.

15] V. Ramesh, (2015) "ATM Based Automated Medical Machine (AMM)" IJSR-International Journal for Scientific Research \& amp; Development| Vol. 3, Issue01, 2015 | ISSN (online): 2321-0613 